Meta

Journal des tradlucteurs

Translators' Journal

\title{
Les « clients » du terminologue
}

\section{Dorothy Nakos-Aupetit}

Volume 21, numéro 4, décembre 1976

URI : https://id.erudit.org/iderudit/003689ar

DOI : https://doi.org/10.7202/003689ar

Aller au sommaire du numéro

Éditeur(s)

Les Presses de l'Université de Montréal

ISSN

0026-0452 (imprimé)

1492-1421 (numérique)

Découvrir la revue

Citer cet article

Nakos-Aupetit, D. (1976). Les « clients » du terminologue. Meta, 21(4), 256-258.

https://doi.org/10.7202/003689ar

Ce document est protégé par la loi sur le droit d'auteur. L’utilisation des services d’Érudit (y compris la reproduction) est assujettie à sa politique d'utilisation que vous pouvez consulter en ligne.

https://apropos.erudit.org/fr/usagers/politique-dutilisation/
Cet article est diffusé et préservé par Érudit.

Érudit est un consortium interuniversitaire sans but lucratif composé de l’Université de Montréal, l’Université Laval et l’Université du Québec à Montréal. Il a pour mission la promotion et la valorisation de la recherche. https://www.erudit.org/fr/ 


\section{Les «clients» du terminologue}

\section{Les appels}

Les personnes qui téléphonent à un bureau de terminologie pour des renseignements peuvent se regrouper en trois catégories principales :

1. La personne d'éducation moyenne, soucieuse néanmoins d'améliorer son vocabulaire. Souvent elle téléphone à un bureau de traduction qui lui conseille de s'adresser au service de terminologie. Elle demande, par exemple, si " développement " peut s'écrire avec un seul "p ", s'il est plus "français" de dire "Indien " ou "Hindou " pour désigner un habitant de l'Inde, ou encore si le féminin de "professeur " est "professeuse" ou "profession". Malheureusement, ce genre de personne n'a pas appris à se servir d'un dictionnaire.

2. L'étudiant ou l'apprenti traducteur qui n'a pas de dictionnaires techniques à sa portée ou qui est trop paresseux pour trouver une expression ou encore qui manque de confiance en lui-même. Il veut vérifier une expression ou carrément vous demander de chercher pour lui. Par exemple: "Pourquoi trouve-t-on tire épelé avec un $y$ dans certains cas?"

3. Des représentants ou directeurs de compagnies, des hauts fonctionnaires ou encore des spécialistes qui veulent l'" expression juste " pour désigner une personne ou un produit. Par exemple, ils aimeraient savoir comment indiquer sur des panneaux "Indian canoe route ", s'il vaut mieux dire "directeur ", " manager ", " gérant ", etc. Souvent les termes qu'ils demandent exigent une certaine réflexion.

En général, les demandes posées par les deux premiers groupes nécessitent très peu de recherches. Souvent, le terminologue donne immédiatement la solution. Pour éviter un travail un peu trop simpliste, le terminologue devrait se doubler d'un documentaliste. Si ce dernier ne peut pas répondre, il consulte le terminologue en lui présentant toutes les données nécessaires pour résoudre le problème (contexte précis, domaine, application, etc.).

\section{La consultation sur place}

En gros, les " clients " d'un bureau de traduction, qui s'adressent au terminologue, se divisent en quatre groupes différents : 
1. L'opportuniste : soit quelqu'un (traducteur ou secrétaire) qui vous accroche au passage, alors que vous vous dirigez vers la bibliothèque pour vous demander un renseignement qu'il pourrait trouver lui-même. Comme vous passez, votre présence lui rappelle l'existence d'un service de terminologie; il s'empresse de vous demander votre opinion. Par exemple: quelle est la différence entre "aéronef " et " avion ". Il y a de fortes chances qu'il la connaisse déjà, mais il n'en est pas sûr. Il peut également vous poser une question plus difficile. Vous lui dites alors que vous voulez toutes les données du problème avant de répondre. Vous lui conseillez de le faire par écrit et de vous laisser le temps de réfléchir. Ce qui l'intéresse, c'est de trouver la solution tout de suite. Il préfère souvent un équivalent douteux, mais obtenu rapidement, à un bon équivalent. Par exemple, il peut vous demander l'équivalent français de "radiacmeter ". Le supplément du Larousse encyclopédique donne "radiamètre ", mais encore faut-il le trouver. Comme il n'a pas la patience d'attendre, il mettra "radiacmètre " dans le texte français.

2. Le bavard: soit la personne qui, sous le prétexte de vous demander un renseignement terminologique (elle n'apporte jamais de document à l'appui), vous parle de tout sauf de terminologie. Le terminologue peut facilement mettre fin au bavardage, d'une façon gentille (à moins qu'il ait envie de bavarder).

3. Le perfectionniste : souvent un réviseur, il vient avec ses multiples papiers, muni de définitions, vous demander de trouver une expression qui, bien souvent, n'existe pas en français. D'après lui, si en anglais on prend la peine d'expliquer un concept abracadabrant en long, en large et en travers, il doit nécessairement exister un terme français pour rendre cette même notion. Quand on connaît le rythme effarant auquel les Américains inventent des mots nouveaux, on ne devrait pas s'étonner de ne trouver aucune expression en français.

Après vérification, vous aurez beau affirmer qu'il est nécessaire, dans ce cas, de créer un terme, il demeure inquiet. Le terminologue doit alors accumuler les arguments, lui démontrer (avec éloquence) que le terme est bien fondé pour enfin le convaincre. Ébloui par votre intelligence (sic), il passe alors dix minutes à vous remercier.

Le perfectionniste peut également rester des heures à votre bureau à discuter, ne serait-ce que pour s'assurer que vous êtes vraiment d'accord avec lui. Par exemple, dans un texte militaire anglais, il trouve "sleeping policemen " pour désigner des obstacles. L'expression est imagée certes, mais le terminologue ne peut pas accepter l'idée du "policier endormi " pour diverses raisons : 1) les francophones voient " le flic " comme un être nerveux, ce qui n'est pas le cas des policiers anglais réputés pour leur flegme; 2) une notion plus "abstraite" semble plus conforme au génie de la langue française dans ce cas. Le perfectionniste peut encore vous demander votre opinion sur un point de syntaxe ou de grammaire. C'est un sujet difficile à satisfaire. 
4. Le chercheur consciencieux: Presque tous les traducteurs et les réviseurs appartiennent à cette catégorie. Ils ont vainement cherché un renseignement à la bibliothèque, ils ont déjà téléphoné à des spécialistes, mais ils ne trouvent rien. Ils viennent alors vous consulter en vous présentant toutes les données du problème.

En général, ils apprécient vos efforts. Ce sont les "fidèles clients " du terminologue (Et, entre nous, les clients que ce dernier préfère!).

DOROTHY NAKOS-AUPETIT 